\title{
HUBUNGAN PENGETAHUAN DAN SIKAP DENGAN UPAYA PENANGGULANGAN KEBAKARAN PADA KARYAWAN DI PD SURABRAJA FOOD INDUSTRY KASUGENGAN KIDUL
}

\author{
Suzana Indragiri*
}

\begin{abstract}
ABSTRAK
Kebakaran merupakan salah satu kecelakaan yang paling sering terjadi selain menimbulkan korban jiwa dan kerugian material, kebakaran juga dapat merusak lingkungan serta gangguan kesehatan yang diakibatkan dari asap kebakaran. Oleh karena itu, untuk meminimalisasi terjadinya kebakaran maka perlu penerapan Keselamatan dan Kesehatan Kerja sebagai upaya pencegahan dan penanggulangan kecelakaan termasuk kebakaran. Pengetahuan, sikap dan upaya karyawan merupakan suatu hal penting dalam menghadapi situasi tanggap darurat bencana kebakaran. Tujuan penelitian ini adalah untuk mengetahui hubungan pengetahuan dan sikap dengan upaya penanggulangan kebakaran pada karyawan di PD Surabraja Food Industry Kasugengan Kidul Kabupaten Cirebon Tahun 2016.

Penelitian ini menggunakan pendekatan kuantitatif dengan desain cross sectional. Populasi dalam penelitian ini yaitu seluruh karyawan di PD Surabraja Food Industry Kasugengan Kidul Kabupaten Cirebon yang berjumlah 106 orang. Teknik pengambilan sampel dalam penelitian ini menggunakan sampling jenuh pada bulan Agustus 2016, instrumen penelitian menggunakan kuesioner dan metode penelitian wawancara, analisa data menggunakan uji statistik chi square. Hasil uji bivariat dengan menggunakan uji statistik, pada variabel pengetahuan menunjukan nilai $\mathrm{p}$ value $=0,035$, hal ini menunjukkan ada hubungan pengetahuan dengan upaya penanggulangan kebakaran dan variabel sikap menunjukan nilai $\mathrm{p}$ value $=0,084$, hal ini menunjukan tidak ada hubungan sikap dengan upaya penanggulangan kebakaran di PD Surabraja Food Industry Kasugengan Kidul Kabupaten Cirebon Tahun 2016.

Perlunya meningkatkan pengetahuan terhadap upaya penanggulangan kebakaran pada karyawan, diharapkan perusahaan mengadakan pelatihan dan sosialisasi terhadap tenaga kerja guna meningkatkan pengetahuan tentang penanggulangan kebakaran di tempat kerja di PD Surabraja Food Industry Kasugengan Kidul Kabupaten Cirebon Tahun 2016.

Kata Kunci : Pengetahuan, Sikap, Upaya Penanggulangan Kebakaran
\end{abstract}

\section{ABSTRACT}

Fire is one of the most common accidents besides causing casualties and material losses, fires can also damage the environment and health problems resulting from smoke fire. Therefore, to minimize the occurrence of fire, the necessary implementation of Health and Safety as prevention and control of accidents including fire. Knowledge, attitudes and behavior of employees is an important thing in the face of a fire emergency response situations.Knowledge, attitude and effort of employees is an important thing in dealing with emergency response situation fire. The purpose this study was to determine the relationship of knowledge and attitude with the fire-fighting effort in employees in PD Surabraja Food Industry Kasugengan Kidul, Cirebon 2016.

This study uses a quantitative approach to the cross-sectional design. The population in this research that all employees in PD Surabraja Food Industry Kasugengan Kidul, Cirebon regency totaling 106 people. The sampling technique in this study using saturation sampling in August 2016, research instruments using a questionnaire and interview research methods, data analysis using chi square test.

Bivariate test results using statistical tests on the knowledge variables showed $\mathrm{p}$ value $=0.035$, this shows there is a relationship of knowledge with the fire-fighting effort and attitude variables showed $\mathrm{p}$ value $=0.084$, this shows there is no correlation with the attitude of fire fighting effort, Companies are expected to conduct training and socialization of labor in order to increase knowledge about fire prevention in PD Surabraja Food Industry Kasugengan Kidul, Cirebon 2016.

The need to improve the knowledge of the fire-fighting effort in employees in PD Surabraja Food Industry Kasugengan Kidul, Cirebon 2016

Keyword : Knowledge, Attitude, Fire Fighting Effort

* Staf Pengajar Program Studi S1 Kesehatan Masyarakat STIKes Cirebon 


\section{PENDAHULUAN}

K3 atau Keselamatan dan Kesehatan Kerja menjadi salah satu bagian penting dalam industrialisasi dewasa ini. Efisiensi biaya dan peningkatan keuntungan semakin diperhatikan seiring dengan penekanan resiko kecelakaan dan penyakit akibat kerja. Terjadinya kecelakaan industri menyebabkan terhambatnya produksi yang akan berdampak pada penurunan produksi serta kerugian perbaikan maupun pengobatan. ${ }^{1}$

Upaya K3 sendiri diperkenalkan dengan mengacu pada peraturan perundangan yang diterbitkan sebagai landasannya. Di samping UU No.1/1970 tentang keselamatan kerja upaya K3 telah dimantapkan dengan UU No.42/2009 tentang kesehatan, yang secara eksplisit mengatur kesehatan kerja. Dalam peraturan perundangan tersebut ditegaskan bahwa dalam setiap tempat kerja wajib diselenggarakan upaya keselamatan dan kesehatan kerja. Hal itu mengatur pada sanksi hukum bila terjadi pelanggaran terhadap ketentuan tersebut. ${ }^{2}$

Oleh karena itu K3 harus dikelola sebagaimana pengelolaan produksi dan keuangan serta fungsi penting perusahaan yang lainnya. Salah satu jenis kecelakaan yang sering dijumpai dan menimbulkan kerugian yang sangat besar adalah kebakaran. Karena apabila terjadi kebakaran akan banyak pihak yang dirugikan, antara lain pihak investor, para pekerja, pemerintah maupun masyarakat luas. ${ }^{3}$

Kebakaran adalah terjadinya api yang tidak dikehendaki. Bagi tenaga kerja, kebakaran perusahaan dapat merupakan penderitaan dan malapetaka khususnya terhadap mereka yang tertimpa kecelakaan dan dapat berakibat cacat fisik, trauma, bahkan kehilangan pekerjaan. Sedangkan bagi perusahaan sendiri akan dapat menimbulkan banyak kerugian, seperti rusaknya dokumen, musnahnya properti serta terhentinya proses produksi. Kebakaran merupakan salah satu kecelakaan yang paling sering terjadi selain menimbulkan korban jiwa dan kerugian material, kebakaran juga dapat merusak lingkungan serta gangguan kesehatan yang diakibatkan dari asap kebakaran tersebut. $^{3}$

Menurut data National Fire Protection Association (NFPA), jumlah kasus kebakaran yang terjadi di Amerika sangat meningkat, dari data yang ada 32.700 kasus kebakaran terjadi dari tahun 2003 hingga 2006, pada tahun 2006 hingga tahun 2008 meningkat $4 \% .^{4}$

Di Indonesia, hingga saat ini kebakaran merupakan bahaya potensial yang masih kerap terjadi baik di tempat kerja maupun pemukiman penduduk. Data kasus kebakaran yang dikutip dari Pusat Laboratorium Fisika Forensik Mabes Polri daritahun 1990-2001 adalah sebagai berikut: tahun 1990-1996, jumlah kejadian: 2.033 kasus (80\% kasus di tempat kerja, 20\% kasus bukan di tempat kerja)dan tahun 1997-2001 jumlah kejadian: 1.121 kasus (76,1\% terjadi di tempat kerja, 23,9\% bukan tempat kerja). Dari data tersebut ternyata tempat kerja lebih besar peluangnya untuk terjadi audit keselamatankebakaran di Indonesia, karena semua unsur yang dapat memicu kebakaran terdapat di tempat kerja, dan ternyata teridentifikasi pula, bahwa 20\% dari kejadian kebakaran berakibat habis total. Gambaran ini menunjukkan bahwa di tempat kejadian tersebut tidak tersedia sumber daya yang memadai untuk menghadapi kejadian kebakaran. Menurut data statistik kebakaran di Jawa Barat, sampai dengan bulan Maret 2015 telah terjadi 165 kali peristiwa kebakaran, dengan perkiraan kerugian material sebesar: Rp. 51.1 Miliar. $^{4}$

Di Kabupaten Cirebon data-data angka kebakaran tahun 2013 telah terjadi kebakaran sebanyak 180 dan 2014 sekitar 150 . Meski trendnya menurun tetap saja hasil analisa setiap bulan masih cukup tinggi atau sekitar 12 kasus kebakaran terjadi di Kabupaten Cirebon dari berbagai macam lokasi dari pemukiman, pabrik maupun lahan kosong. Untuk meminimalisasi terjadinya kebakaran maka perlu penerapan Keselamatan dan Kesehatan Kerja sebagai upaya pencegahan dan penanggulangan kecelakaan termasuk kebakaran. Pencegahan dan penanggulangan kebakaran adalah semua tindakan yang berhubungan dengan pencegahan, pengamatan dan pemadaman kebakaran dan meliputi perlindungan jiwa dan keselamatan manusia serta perlindungan harta kekayaan. $^{5}$

Berdasarkan uraian tersebut penulis tertarik melakukan penelitian tentang hubungan pengetahuan dan sikap dengan upaya penanggulangan kebakaran pada karyawan di PD Surabraja Food Industry Kasugengan Kidul Kabupaten CirebonTahun 2016. Tujuan penelitian mengetahui 
hubungan pengetahuan dan sikap dengan upaya penanggulangan kebakaran pada karyawan di PD Surabraja Food Industry Kasugengan Kidul Kabupaten Cirebon Tahun 2016.

\section{METODE PENELITIAN}

Penelitian ini dilakukan dengan menggunakan pendekatan kuantitatif, dengan desain Cross Sectional. Faktor independennya adalah pengetahuan dan sikap, dan faktor dependennya yaitu upaya penanggulangan kebakaran. Populasi dalam penelitian ini adalah seluruh karyawan di PD Surabraja Food Industry Kasugengan Kidul Kabupaten Cirebon dengan jumlah 106 karyawan pada bulan Juni tahun 2016. Pengambilan sampel ditentukan dengan cara sampling jenuh yaitu teknik penentuan sampel bila semua anggota populasi digunakan sebagai sampel. Jadi jumlah sampel dalam penelitian ini adalah sebesar 106 karyawan.

\section{HASIL PENELITIAN}

\section{Analisis Univariat}

\section{Pengetahuan}

Tabel 1. Distribusi frekuensi responden berdasarkan pengetahuan tentang upaya penanggulangan kebakaran di PD Surabraja Food Industry Kasugengan Kidul Kabupaten Cirebon Tahun 2016

\begin{tabular}{llccc}
\hline No & Pengetahuan & F & $\begin{array}{c}\text { Persentase } \\
(\%)\end{array}$ \\
\hline 1 & Kurang Baik & 62 & 58,5 \\
2 & Baik & 44 & 41,5 \\
\hline & Iumlah & 106 & 100 \\
\hline
\end{tabular}

Berdasarkan tabel 1 dapat diketahui bahwa sebanyak 58,5\% responden memiliki pengetahuan yang kurang baik tentang upaya penanggulangan kebakaran.

\section{Sikap}

Tabel 2. Distribusi frekuensi responden berdasarkan sikap tentang upaya penanggulangan kebakaran di PD Surabraja Food Industry Kasugengan Kidul Kabupaten Cirebon Tahun 2016

\begin{tabular}{llcc}
\hline No & Sikap & F & Persentase (\%) \\
\hline 1 & Kurang Baik & 56 & 52,8 \\
2 & Baik & 50 & 47,2 \\
\hline & Iumlah & 106 & 100 \\
\hline
\end{tabular}

Berdasarkan tabel 2 dapat diketahui bahwa sebanyak 52,8\% responden memiliki sikap yang kurang baik tentang upaya penanggulangan kebakaran.

\section{Upaya penanggulangan kebakaran}

Tabel 3. Distribusi Frekuensi Responden Berdasarkan Upaya Penanggulangan Kebakaran di PD Surabraja Food Industry Kasugengan Kidul Kabupaten Cirebon Tahun 2016

\begin{tabular}{|c|c|c|c|}
\hline No & Upaya Penanggulangan Kebakaran & $\mathrm{F}$ & Persentase $(\%)$ \\
\hline 1 & Kurang Baik & 55 & 51,9 \\
\hline 2 & Baik & 51 & 48,1 \\
\hline & Iumlah & 106 & 100 \\
\hline
\end{tabular}


Berdasarkan tabel 3 dapat diketahui bahwa sebanyak 51,9\% responden memiliki upaya yang kurang baik tentang upaya penanggulangan kebakaran.

\section{Analisis Bivariat}

\section{Hubungan Antara Pengetahuan Dengan Upaya Penanggulangan Kebakaran}

Tabel 4. Hubungan Antara Pengetahuan Dengan Upaya Penanggulangan Kebakaran Pada karyawan di PD Surabraja Food Industry Kasugengan Kidul Kabupaten Cirebon Tahun 2016

\begin{tabular}{|c|c|c|c|c|c|c|c|c|}
\hline \multirow{3}{*}{ No } & \multirow{3}{*}{ Pengetahuan } & \multicolumn{4}{|c|}{$\begin{array}{c}\text { Upaya Penanggulangan } \\
\text { Kebakaran }\end{array}$} & \multicolumn{2}{|c|}{ Jumlah } & \multirow[t]{3}{*}{$p$ value } \\
\hline & & \multicolumn{2}{|c|}{ Kurang Baik } & \multicolumn{2}{|c|}{ Baik } & \multirow[b]{2}{*}{$\mathbf{n}$} & \multirow{2}{*}{$\%$} & \\
\hline & & $\mathrm{n}$ & $\%$ & $\mathrm{n}$ & $\%$ & & & \\
\hline 1 & Kurang Baik & 38 & 61,3 & 24 & 38,7 & 62 & 100 & 0,035 \\
\hline 2 & Baik & 17 & 38,6 & 27 & 61,4 & 44 & 100 & \\
\hline Total & & 55 & 51,9 & 51 & 48,1 & 106 & 100 & \\
\hline
\end{tabular}

Dari hasil uji statistik dengan menggunakan uji chi square didapatkan nilai $\mathrm{p}$ value $=0,035$ hal ini menunjukan ada hubungan yang bermakna antara pengetahuan dengan upaya penanggulangan kebakaran pada karyawan di PD Surabraja food industry Kasugengan Kidul Kabupaten Cirebon tahun 2016.

\section{Hubungan Antara Sikap Dengan Upaya Penanggulangan Kebakaran}

Tabel 5. Hubungan Antara Sikap Dengan Upaya Penanggulangan Kebakaran Pada karyawan di PD Surabraja Food Industry Kasugengan Kidul Kabupaten Cirebon Tahun 2016

\begin{tabular}{|c|c|c|c|c|c|c|c|c|}
\hline \multirow{3}{*}{ No } & \multirow{3}{*}{ Sikap } & \multicolumn{4}{|c|}{$\begin{array}{c}\text { Upaya Penanggulangan } \\
\text { Kebakaran }\end{array}$} & \multicolumn{2}{|c|}{ Jumlah } & \multirow{3}{*}{$p$ value } \\
\hline & & \multicolumn{2}{|c|}{ Kurang Baik } & \multicolumn{2}{|c|}{ Baik } & \multirow[b]{2}{*}{$\mathrm{n}$} & \multirow{2}{*}{$\%$} & \\
\hline & & $\mathrm{n}$ & $\%$ & $\mathrm{n}$ & $\%$ & & & \\
\hline 1 & Kurang Baik & 34 & 60,7 & 22 & 39,3 & 56 & 100 & 0,084 \\
\hline 2 & Baik & 21 & 42,0 & 29 & 58,0 & 50 & 100 & \\
\hline Total & & 55 & 51,9 & 51 & 48,1 & 106 & 100 & \\
\hline
\end{tabular}

Dari hasil uji statistik dengan menggunakan uji chi square didapatkan nilai $p$ value $=0,084$ hal ini menunjukan tidak ada hubungan yang bermakna antara sikap dengan upaya penanggulangan kebakaran pada karyawan di PD Surabraja food industry Kasugengan Kidul Kabupaten Cirebon tahun 2016.

\section{PEMBAHASAN}

Hubungan Antara Pengetahuan Dengan Upaya Penanggulangan Kebakaran

Berdasarkan hasil penelitian diketahui bahwa ada hubungan pengetahuan dengan upaya penanggulangan kebakaran pada karyawan di PD Surabraja Food Industry Kasugengan Kidul Kabupaten Cirebon. Hasil ini didasarkan pada uji statistik diperoleh p-value sebesar 0,035.

Menurut Soekidjo Notoatmodjo pengetahuan adalah hasil "tahu"dan ini terjadi setelah orang melakukan penginderaan terhadap suatu objek tertentu. Penginderaan terjadi melalui panca indra manusia, yakni: indra penglihatan, pendengaran, penciuman, rasa dan raba. Sebagian besar pengetahuan manusia diperoleh melalui mata dan telinga. Pengetahuan atau kognitif merupakan domain yang sangat penting untuk terbentuknya tindakan seseorang (over behaviour). Karena dari pengalaman dan penelitiannya ternyata upaya yang didasarkan oleh pengetahuan akan lebih langgeng daripada upaya yang tidak didasari oleh pengetahuan. ${ }^{6}$ 
Pengetahuan yang didapat pekerja merupakan pengalaman dan pelatihan yang didapat dari tempat kerja sebelumnya (perusahaan). Sehingga upaya penanggulangan kebakaran yang ditunjukkan oleh pekerja merupakan kesadaran pekerja. Pengetahuan yang didapatkan merupakan analisis pekerja terhadap bahaya yang terjadi sehingga penanggulangan kebakaran didasarkan kemampuan pekerja untuk menjabarkan, membedakan, memisahkan dan mengelompokkan bahaya yang ada ditempat kerja.

Hasil penelitian ini sejalan dengan penelitian yang dilakukan oleh Anita (2008) yang menyatakan bahwa ada hubungan antara tingkat pengetahuan karyawan dengan upaya pencegahan kebakaran. ${ }^{7}$ Hasil tersebut didukung oleh penelitian Indradi (2008) yang menyatakan bahwa ada hubungan antara pengetahuan dengan praktik keselamatan kebakaran. ${ }^{8}$

\section{Hubungan Antara Sikap Dengan Upaya Penanggulangan Kebakaran}

Berdasarkan hasil penelitian diketahui bahwa tidak ada hubungan sikap dengan upaya penanggulangan kebakaran pada karyawan di PD Surabraja Food Industry Kasugengan Kidul Kabupaten Cirebon. Hasil ini didasarkan pada uji statistik diperoleh p-value sebesar 0,084.

Menurut Gerungan, sikap merupakan pendapat maupun pendangan seseorang tentang suatu objek yang mendahului tindakannya. Sikap tidak mungkin terbentuk sebelum mendapat informasi, melihat atau mengalami sendiri suatu objek. Sikap dapat berubah-ubah sesuai dengan keadaan lingkungan disekitar individu yang bersangkutan pada saat-saat dan tempat yang berbeda. Sikap dinyatakan dalam 3 domain ABC, yaitu Affect, Behaviour, dan Cognition. Affect adalah perasaan yang timbul (senang, tidak senang), Behaviour adalah perilaku yang mengikuti perasaan itu (mendekat, menghindar) dan Cognition adalah penilaian terhadap objek sikap (bagus, tidak bagus). ${ }^{9}$

Hubungan antara sikap dengan upaya tidak sepenuhnya dimengerti, namun bukti adanya hubungan tersebut cukup banyak (Green) tetapi pada penelitian ini tidak ditemukan adanya hubungan antara sikap dengan upaya tersebut. Suatu sikap belum otomatis terwujud dalam suatu tindakan. Untuk terwujudnya sikap agar menjadi tindakan yang nyata diperlukan faktor pendukung atau kondisi fasilitas yang memungkinkan. Tindakan seseorang terhadap stimulus tertentu akan banyak ditentukan oleh bagaimana kepercayaan dan perasaanya terhadap stimulus tersebut. Secara biologis, sikap dapat dicerminkan dalam suatu bentuk tindakan, namun tidak pula dapat dikatakan bahwa sikap dan tindakan memiliki hubungan yang sistematis. ${ }^{10}$

Menurut analisa penulis, tidak adanya hubungan antara sikap dengan upaya penanggulangan kebakaran dikarenakan adanya faktor lain baik faktor internal maupun faktor eksternal. Faktor internal diantaranya keadaan psikologis seperti ketidakyakinan responden saat akan melakukan penanggulangan kebakaran dan rasa emosional yang muncul seperti cemas, tegang, dan gugup, sedangkan untuk faktor eksternal yaitu kurangnya fasilitas alat pemadam kebakaran yang tersedia seperti tidak adanya APAR atau HYDRAN.

\section{SIMPULAN}

1. Ada hubungan antara pengetahuan dengan upaya penanggulangan kebakaran pada karyawan di PD Surabraja Food Industry Kasugengan Kidul Kabupaten Cirebon Tahun 2016.

2. Tidak ada hubungan antara sikap dengan upaya penanggulangan kebakaran pada karyawan di PD Surabraja Food Industry Kasugengan Kidul Kabupaten Cirebon Tahun 2016.

\section{SARAN}

1. Bagi Perusahaan

1) Diharapkan perusahaan mengadakan pelatihan dan simulasi tentang penanggulangan kebakaran terhadap karyawan guna meningkatkan pengetahuan tentang penanggulangan kebakaran di tempat kerja.

2) Diharapkan perusahaan dapat melakukan evaluasi terhadap pelaksanaan standar operasional prosedur (SOP) pada saat penanggulangan kebakaran di PD Surabraja Food Industry Kasugengan Kidul Kabupaten Cirebon, sehingga dapat menghindari atau mengurangi resiko terjadinya kebakaran. Selain itu perusahaan hendaknya memberikan penghargaan atau reward pada 
karyawan yang mempunyai pengetahuan, sikap dan upaya yang baik tentang penanggulangan kebakaran.

\section{Bagi Karyawan}

1) Mengikuti pelatihan dan sosialisasi untuk lebih meningkatkan pengetahuan tentang penanggulangan kebakaran di PD Surabraja Food Industry Kasugengan Kidul Kabupaten Cirebon.

2) Melaksanakan dan mengikuti peraturan tentang penanggulangan kebakaran sesuai SOP untuk lebih meningkatkan tindakan penanggulangan kebakaran di PD Surabraja Food Industry Kasugengan Kidul Kabupaten Cirebon.

3. Bagi Peneliti Lain

Diharapkan agar dapat dilakukan penelitian lebih lanjut pada variabel-variabel yang belum diteliti, dan menambahkan jumlah sampel serta dengan analisis multivariat agar diketahui faktor apa saja yang paling berpengaruh dalam upaya penanggulangan kebakaran.

\section{DAFTAR PUSTAKA}

1. Sholihah Isnaini. APAR ( Alat Pemadam Api Ringan ) dan Instalasi HYDRANT sebagai salah satu upaya pencegahan dan penanggulangan kebakaran di area pabrik I PT.PETROKIMIA Gresik tahun 2010. Laporan Gresik: Fakultas Kedokteran Universitas 11 Maret; 2010

2. Arif Supono. Himpunan peraturan Perundang-undangan Keselamatan. Jakarta: Kementrian Tenaga Kerja dan Transmigrasi; 2011

3. Suma'mur, Keselamatan Kerja dan Pencegahan Kecelakaan. Jakarta: CV Haji Masagung; 1089.2528

4. Zainul Arifin. Pegangan Pekerja DAMKAR DKI JAKARTA. Dalam: Zainul Arifin. Pedoman Pelatihan Pemadam Kebakaran. Jakarta; 2010

5. Arif Budi. Pedoman Pekerja DAMKAR Kabupaten Cirebon. Dalam: Arif Budi. Pedoman Pekerja Pemadam Kebakaran. Cirebon; 2010

6. Soekidjo Notoatmodjo. Kesehatan Masyarakat Ilmu dan Seni. Rineka Cipta; 2003

7. Anita Mertiana. Hubungan Pelatihan Tingkat Pengetahuan dan Sikap Karyawan terhadap Upaya Pencegahan Kebakaran ( studi di RSD dr. H Koesnadi Bondowoso). Jurnal ; 2008. Tersedia dari : http://adln.lib.unair.ac.id/.

8. Indradi. Beberapa Faktor yang Berhubungan Dengan Praktik Keselamatan Kebakaran operator SPBU dalam Upaya Pencegahan Kebakaran di Areal SPBU Kecamatan Ngaliyan Semarang Barat. Jurnal; 2008. Tersedia dari: http://core.ac.uk/.

9. Sarwono, S.W. Psikologi Dalam Praktik. Jakarta: Restu Agung; 2003

10. Soekidjo Notoatmodjo. Pendidikan dan Perilaku Kesehatan. Jakarta: Rineka Cipta; 2003 